\title{
Entrepreneurs embrace competition: evidence from a lab-in-the-field study
}

\author{
Diemo Urbig (iD - Werner Bönte • Vivien D. Procher • \\ Sandro Lombardo
}

Accepted: 22 January 2019/Published online: 26 February 2019

(C) The Author(s) 2019

\begin{abstract}
Referring to Isreal M. Kirzner (1973) and Schumpeter (1934), who emphasized the competitive nature of entrepreneurship, this study investigates whether potential and revealed entrepreneurs are more likely to seek competition than non-entrepreneurs. We provide a conceptual framework that links entrepreneurship to three facets of individual competitiveness drawn
\end{abstract}

D. Urbig $(\bowtie) \cdot$ W. Bönte $\cdot$ S. Lombardo

Schumpeter School of Business and Economics, University of Wuppertal, Gaußstraße 20, 42119 Wuppertal, Germany

e-mail: urbig@uni-wuppertal.de

D. Urbig · W. Bönte

School of Public \& Environmental Affairs, Institute for Development Strategies, Indiana University, 1315 East 10th Street, Bloomington, IN 47405, USA

D. Urbig

Jheronimus Academy of Data Science, Sint Janssingel 92, 5211 Den Bosch, DA, The Netherlands

D. Urbig

School of Industrial Engineering, Eindhoven University of Technology, PO Box 513, 5600 Eindhoven, MB, The Netherlands

W. Bönte

Jackstädt Center of Entrepreneurship and Innovation Research, University of Wuppertal, Gaußstr. 20, 42119 Wuppertal, Germany

V. D. Procher

Grenoble Ecole de Management, Univ Grenoble Alpes ComUE, 12 rue Pierre Sémard, 38000 Grenoble, France

V. D. Procher

RWI - Leibniz-Institut für Wirtschaftsforschung,

Hohenzollernstraße 1-3, 45128 Essen, Germany from economic, entrepreneurship, and psychological research: a desire to win, striving for personal development, and an enjoyment of competition. Following economic research linking competitive behavior in experiments to career choices, we conduct a lab-in-the-field study and demonstrate that entrepreneurs are more likely to enter competitions than non-entrepreneurs. Accounting for individual desires to win and masteryrelated achievement motivations, our results indicate that entrepreneurs tend to enter competition for the sake of competition itself rather than for the prospect of winning it or personal development. Our results suggest that enjoyment of competition might be an additional factor driving entrepreneurs' market entry decisions beyond well-known factors like overconfidence and risk-taking.

Keywords Enjoyment of competition · Individual competitiveness · Entrepreneurship · Behavioral economics $\cdot$ Lab-in-the-field experiment

JEL L 26· C9·D9
I am asserting that entrepreneurship and competition are two sides of the same coin: that entrepreneurial activity is always competitive and that competitive activity is always entrepreneurial (Kirzner 1973, p. 94) 


\section{Introduction}

Isreal M. Kirzner's above-quoted assertion tightly links entrepreneurship to competition, suggesting that individuals who embrace competition might be those who are attracted to entrepreneurship. Consistently, Joseph A. Schumpeter describes entrepreneurs as being driven by "the will to conquer; the impulse to fight, to prove oneself superior to others" (Schumpeter 1934, p. 93). Despite Kirzner's and Schumpeter's well-known disagreement on the economic function of the entrepreneur, ${ }^{1}$ these two distinguished theoreticians seem to agree that entrepreneurial activity is inherently competitive and that entrepreneurs tend to embrace competition.

While Kirzner (1973) and Schumpeter (1934) notably influence modern entrepreneurship research in many ways, their observation that entrepreneurship is linked to competition, thus implying that becoming an entrepreneur means selecting into a particularly competitive environment, is almost completely ignored in entrepreneurship research. Reviewing the extensive literature on the personality of entrepreneurs, Kerr et al. (2018) highlight several personality traits, but do not emphasize the attitudes of individuals toward competition, such as those described by Schumpeter (1934). Competition only indirectly enters the review through entrepreneurs' optimistic beliefs about their abilities relative to others. Furthermore, Rauch and Frese (2007) introduce, based on a survey of expert researchers, entrepreneurs' personality characteristics that can be matched to specific tasks of entrepreneurs. While Kirzner (1973) describes the entrepreneurial task as inherently competitive, individuals' attitudes toward competition are not considered by Rauch and Frese (2007) as one of the personality characteristics of entrepreneurs that match with the specific demands of entrepreneurial environments. Outside the specific context of entrepreneurship, behavioral economists are now studying the link between career choices and individual competitiveness, denoting individuals' general tendency to favor competitive over noncompetitive situations (Niederle 2017; Niederle and Vesterlund 2007). Results of empirical studies suggest that individual competitiveness, as measured by economic experiments, is related to selection into more competitive educational and occupational environments (e.g.,

\footnotetext{
${ }^{1}$ Kirzner (1973) suggests that entrepreneurial activities tend to drive markets toward equilibrium, while Schumpeter (1934) suggests that that these activities are the driving force behind market disequilibria.
}

Buser et al. 2014, 2017; Reuben et al. 2015, 2017; Almås et al. 2016). However, entrepreneurship, as an environment particularly attractive for competitive individuals, receives equally little attention in economic research as it does in entrepreneurship research (see Bönte and Piegeler 2013, and Holm et al. 2013, as exceptions).

In this study, we address the relationship between entrepreneurship and individual competitiveness. We introduce a general framework highlighting different facets of individual competitiveness. Thereby, we connect entrepreneurship research to psychological research, which identifies three facets of competitiveness that are related to different motives to enter competitive environments, i.e., a desire to win, personal development and mastery of tasks, as well as enjoyment of competition (e.g., Ryckman et al. 1990, 1996; Newby and Klein 2014; Houston et al. 2002b). While individual competitiveness is rarely, and the individual facets were not, addressed explicitly in the entrepreneurship literature, two of the three facets of competitiveness are at least indirectly linked to constructs discussed in entrepreneurship research. First, a strong desire to win can result in greater efforts to win a competition but may also lead to aggressive or even unethical behavior (Ryckman et al. 1990; Houston et al. 2002a; Newby and Klein 2014). A positive association between such behaviors and entrepreneurship is already demonstrated in the literature (e.g., Berge et al. 2015; Utsch et al. 1999; Hmieleski and Lerner 2016; Levine and Rubinstein 2017). Second, striving for personal development and mastery of tasks may also affect an individual's decision to enter competitions (Ryckman et al. 1996; Newby and Klein 2014). Due to its reference to the mastery of tasks, this facet of competitiveness is closely related to achievement motivation (McClelland 1965). Some authors also relate achievement motivation to the desire to outperform others (Cassidy and Lynn 1989). Hence, two facets of individual competitiveness can be linked to what some researchers refer to as intrinsic and extrinsic achievement motivations (Hart et al. 2007), with personal development competitiveness reflecting intrinsic and willingness to win reflecting extrinsic achievement motivation. Achievement motivation, in general, is often viewed as one of the most prominent characteristics of entrepreneurs (e.g., McClelland 1965; Rauch and Frese 2007).

The relationship between entrepreneurship and enjoyment of competition, however, is not yet investigated in entrepreneurship research. In this study, we hypothesize that that entrepreneurs decide to enter a competition for 
the sake of competition itself, independent of the prospect of winning the competition or personal development and mastering the tasks in the competition and, hence, independent of achievement motivations. If entrepreneurs had a stronger general tendency to favor competitive over non-competitive environments than non-entrepreneurs and if this tendency was at least partially driven by enjoyment of competition, this could have relevant practical implications. For instance, among the three facets of individual competitiveness, the particular enjoyment of competition might provide an additional explanation for potentially excessive market entry by entrepreneurs and perseverance in the face of low odds of success and in the face of a lack of controllability, e.g., due to the influence of pure chance, beyond the well-known factors such as overconfidence (cf., Camerer \& Lovallo 1999) and high willingness to take risks (e.g., Caliendo et al. 2009; Wu and Knott 2006). ${ }^{2}$

Our study builds on a strand of economic literature demonstrating that individuals selecting into competitive situations in incentivized economic experiments also select into more competitive careers, such as a career in financial industries or choosing more prestigious academic tracks (e.g., Almås et al. 2016; Buser et al. 2017; Buser et al. 2014; Reuben et al. 2015). Following these studies, we adapt an experimental design introduced by Niederle and Vesterlund (2007), where participants perform well-defined tasks and choose between two performance-related payment schemes. Participants can choose between a non-competitive piece-rate payment scheme and a competitive winner-takes-all tournament payment scheme. We conduct a "lab-in-the-field" study of 224 visitors at a shopping mall in a large German city. For the lab-in-the-field study, we created an artifactual (i.e., not related to a particular professional or life context) experimental environment in which participants made decisions and could earn money. The participants then split into three groups: (1) those who once had or still have their own business, (2) those who have not had an own business but intend to start one, and (3) those who have not and do not want to have an own business. We

\footnotetext{
${ }^{2}$ In fact, there is substantial work demonstrating a lack of relevance of risk preferences (e.g., Busenitz and Barney 1997; Miner and Raju 2004; Palich and Bagby 1995; Wu and Knott 2006). In particular, Holm et al. (2013) report that general risk preferences do not distinguish entrepreneurs from others, but only preferences related to risks in strategic interaction, including competitions and, consequently, enjoyment of competition might, in fact, be more important and explain some of the seeming risk taking of entrepreneurs.
}

demonstrate that entrepreneurs - both revealed entrepreneurs (individuals who have had their own businesses) and potential entrepreneurs (who consider having an own business a possible future option) - are more likely to select into competition than non-entrepreneurial individuals (who have not had their own business and have no intention of starting one). ${ }^{3}$

Our study makes two main contributions to the literature. First, to the authors' best knowledge, this is the first study examining the link between entrepreneurship and individual competitiveness with a specific focus on enjoyment of competition, which implies a preference for competition that is independent of individuals' odds of winning and independent of whether or not the competition is based on mastery of skill-based tasks. We employ an experimental design that allows us to examine the extent to which entrepreneurs' tendency to select into competitive situations is driven by enjoyment of competition rather than driven by a desire to win or achievement motives. We isolate enjoyment of competition from a desire to win by showing that this effect does not depend on entrepreneurs' levels of confidence in winning the competition. If individuals enter competitions despite believing that they are unlikely to win, their preferences for competition are not solely driven by their desire to win. ${ }^{4}$ Moreover, we isolate enjoyment of competition from achievement motivations by showing that the effect holds for both a skill-related task, i.e., verifying simple single-digit equations (Mayr et al. 2012), and a skill-independent task, i.e., rolling dice (Ifcher and Zarghamee 2016). In contrast to the mathbased competition, the outcomes of the dice task are determined by chance only and, therefore, individuals' selection into this dice-based competition does not tend to be driven by skill-related considerations, such as individuals' striving for personal development or achievement motivations. Since we find that entrepreneurs are more competitively inclined than non-

\footnotetext{
${ }^{3}$ For the sake of this study, we follow Blanchflower and Oswald (1998) and use the terms entrepreneurship and self-employment interchangeably by employing a conceptualization of entrepreneurship of a medium scope; that is, beyond individuals starting their own business with the intention to grow and employ other people, we also include individuals who run their own business without employees or without the intention to grow. However, we exclude people who act entrepreneurially in an employment position, such as managers or any sort of corporate entrepreneurs or employees who manage corporate spin-offs without actually owning that spin-off.

${ }^{4}$ In fact, if individuals have a strong desire to win and do not believe that they can win, it is less likely that they enter competitive environments.
} 
entrepreneurs, even when controlling for the other two facets of competition, our results demonstrate the relevance of enjoyment of competition as antecedent to selection into competition. In sum, our study on enjoyment of competition extends and complements research focusing on behavior in competitions, which suggests that entrepreneurs behave more aggressively and possibly even ruthlessly when competing (Utsch et al. 1999; Hmieleski and Lerner 2016; Levine and Rubinstein 2017) and that mastery of tasks and outperforming others is associated with entrepreneurship (McClelland 1965; Rauch and Frese 2007).

Our second main contribution to the literature is our finding that the association of entrepreneurship and enjoyment of competition holds for both revealed entrepreneurs, who have experience in entrepreneurship, and potential entrepreneurs, who have no entrepreneurial experience but are considering to start their own businesses in the future. This observation tentatively suggests that individuals' behavior in economic experiments is related to selection into entrepreneurship. Thereby, our study contributes to research linking competitive behavior in such experiments to career choices (e.g., Almås et al. 2016; Buser et al. 2014, 2017), a research stream that does not yet acknowledge entrepreneurship as a career that is especially attractive to individuals embracing competition.

In the remainder of this study, we first distinguish individual competitiveness as a tendency to favor competitive over non-competitive environments from other constructs using the same label. We then discuss the three distinct facets of individual competitiveness and their critical contingencies, which need to be distinguished to isolate enjoyment of competition. Building on this discussion, we then outline our empirical approach. Following the report of our results and a large set of robustness checks, we discuss how our findings contribute to entrepreneurship and economics research.

\section{Conceptual background}

In psychological, economic, and entrepreneurship research, the notion of competitiveness has various meanings. In order to clarify our conceptualization of individual competitiveness, we separate our conceptualization, which focuses on individuals' selection into competitive environments, from conceptualizations focusing on the ability to win in competitions or on behavior within competitive environments. We then highlight three facets of individual competitiveness, namely enjoyment of competition, desire to win, and personal development, and discuss how these facets can be linked to entrepreneurship research. Thereby, we document that enjoyment of competition is the only one of the three facets that is not yet convincingly linked to entrepreneurship.

\subsection{Individual competitiveness}

We follow existing psychological and economic research focusing on individual competitiveness defined as individuals' general tendency to favor competitive over non-competitive environments (Niederle 2017; Niederle and Vesterlund 2007; Bönte et al. 2017a). This preference is distinct from risk preferences and overconfidence. As any competition implies a chance of winning or losing, both risk preferences and overconfidence may make competitive environments more attractive, but they both do not relate to a unique preference for competitive versus non-competitive environments (Niederle 2017; Niederle and Vesterlund 2007; Bönte et al. 2017a). Competitive environments are characterized by institutions where individuals' goals are not simultaneously achievable given the sets of possible behaviors. Hence, in competitive environments, every attempt of individuals to get closer to their own goals makes it less likely for other individuals to achieve their goals (Deutsch 1949; Lazear 1999). This negative relationship of an individual's goals versus other individuals can be established, for instance, by "the perceived presence of a rival or a group of competitors who serve as performance standards for the individual" (Smither and Houston 1992, p. 408). This very general definition of competitive environments also comprises environments where the performances of individuals are not under their control or where their performances are affected neither by their efforts nor by their abilities and skills. According to this conceptualization of individual competitiveness, competitive individuals select into competitiveness environments because they have preferences over particular economic institutions linking individuals' performances to their rewards, but not because they have preferences over particular tasks they are competing in.

Our conceptualization differs from two other conceptualizations of competitive individuals that are used in previous research, but relate to completely different 
settings and mechanisms. First, competitiveness is sometimes defined as individual ability to win competitions or to perform better than others (e.g., Manning and Taylor 2001; Hönekopp et al. 2006). While the ability to win a competition may indirectly affect individuals' decisions to select into competitions, a high probability of winning does not imply that an individual has a unique preference for competitive over noncompetitive environments (Niederle and Vesterlund 2007). A general tendency to favor competitive environments, as suggested in this study, implies that an individual tends to select into competitions, irrespective of the own ability to win.

Second, following economic research (Croson and Gneezy 2009), we separate the tendency to enter competitive environments from individuals' behavior within competitive environments. Alfred Marshall (1920), for instance, asserts that "a manufacturer or a trader is often stimulated much more by the hope of victory over his rivals than by the desire to add something to his fortune" (p.19) and, hence, accepts lower profits within a competition for the sake of winning. Aggressive behavior in competitive environments does not necessarily imply, however, that individuals generally like situations in which they compete with others. For instance, individuals who dislike competitions may be forced to enter competitive environments and may respond to this by competing aggressively. While aggressive behavior in competitions is already associated with entrepreneurs (e.g., Utsch et al. 1999; Hmieleski and Lerner 2016), such behavioral tendencies within competitive environments are distinct from preferences to enter competitions. ${ }^{5}$ Relatedly, individuals maximizing own rewards relative to others' rewards are also considered to be competitive individuals (e.g., van Lange et al. 1997; Fehr and Schmidt 1999) and these distributional preferences are linked to selection into entrepreneurship (e.g., Weitzel et al. 2010). While significant correlations

\footnotetext{
${ }^{5}$ In psychological research, the individual competitiveness as a preference for competition and behavior within competitions are sometimes viewed as one construct. For instance, hypercompetitiveness as "an indiscriminate need by individuals to compete and win (and to avoid losing) at any cost" (Ryckman et al. 1990, p. 630) and the competitiveness dimension in the work and family orientation questionnaire defined as "enjoyment of interpersonal competition and the desire to win and be better than others" (Spence \& Helmreich, 1978, p. 41) clearly mix preferences to compete with preferences for specific behaviors within competitions. Depending on the specific research question, such a combination can reduce the ability to sufficiently differentiate between mechanisms affecting individuals' behaviors related to selection into and behavior in competitions.
}

between such distributional preferences and individual competitiveness are reported (Bartling et al. 2009), distributional preferences also differ from our conceptualization of individual competitiveness, because they relate to behavior in contexts where individuals' rewards are mutually dependent on one another, that is, to behavior in competitive environments, but not to preferences to select into such environments. In sum, the two presented alternative conceptualizations of competitiveness refer to individuals' behaviors and performances within competition, but do not focus on selection into competitive environments, which is the focus of our research.

\subsection{Enjoyment of competition as a facet of individual competitiveness}

Individuals may voluntarily select into competitive environments for different reasons. Psychological research identifies different facets of individual competitiveness, each relating to a distinct motive that makes competitive environments attractive to individuals (Newby and Klein 2014; Helmreich and Spence 1978; Houston et al. 2002a). Three facets emerge as important: the desire to win, personal development, and enjoyment of competition (Ryckman et al. 1990, 1996; Houston et al. 2002b; Newby and Klein 2014). While entrepreneurs' desires to win and their need for achievement and personal development are already indirectly addressed in entrepreneurship research (e.g., Utsch et al. 1999; Levine and Rubinstein 2017; McClelland 1965; Rauch and Frese 2007), enjoyment of competition is neither directly nor indirectly investigated. Therefore, we focus on enjoyment of competition, reflecting the non-monetary benefits associated with competing against others. These intrinsic benefits are related to the institution of competition itself and do not depend on the outcome of a competition, i.e., whether a competition is won or lost. Moreover, these benefits that arise from competing with other individuals are independent of the particular tasks carried out in the competition. This implies that enjoyment of competition results from competing, irrespective of performing a particular task, irrespective of demonstrating superior skills, and irrespective of winning a competition.

Enjoyment of competition can be distinguished from individuals' willingness to win (Newby and Klein 2014; Ryckman et al. 1990). Individuals with a desire to win may feel that they need to win and avoid losing at any cost (Ryckman et al. 1990), thus competing for the sake 
of winning, independent of the associated rewards. These individuals are likely to invest more effort and accept higher costs to increase the odds of winning than individuals without such desires. More importantly, in order to have a chance of winning a competition, individuals must enter a competition. Hence, the desire to win can be an important motivation to seek competitive rather than non-competitive environments. This, however, does not imply that individuals with a strong desire to win also have a general tendency to favor competitive over non-competitive environments. On the contrary, individuals with a strong desire to win might even shy away from competitions they believe that they are not able to win (Connelly et al. 2014; Coffey and Maloney 2010). Hence, the desire to win may affect the likelihood that individuals select into competitive environments, but this effect is - in contrast to the effect of enjoyment of competition-conditioned on individuals' expectations of winning the competition. Through this inherent interaction between confidence in winning a competition as a belief and the desire to win as a preference, we are able to empirically discriminate between a desire to win as an expectancy-dependent facet and other facets of individual competitiveness, including the enjoyment of competition.

Enjoyment of competition can also be distinguished from a third facet of individual competitiveness that is driven by personal development motives (Newby and Klein 2014; Ryckman et al. 1996) and related achievement motivations (Nicholls 1984; Elliot and McGregor 1999). Individuals competing to satisfy personal development goals do not focus on winning a competition, but rather seek mastery of a given task (Ryckman et al. 1996). Similarly, achievement motivations drive individuals to strive for accomplishments and the mastering of skills; hence, relating to tasks that require skills or allow individuals to display their skills (Nicholls 1984; Elliot and McGregor 1999). ${ }^{6}$ Consequently, personal development and achievement motivations can be expected to be particularly relevant for selection into competition based on tasks that require and challenge

\footnotetext{
${ }^{6}$ Since some researchers equate competitiveness with achievement motivation, it is important to note that the here-discussed differences imply that both are distinct constructs. Competitiveness only matters for competitive environments, but need for achievement may also affect engagement in tasks performed in non-competitive environments. Hence, not all competitive individuals are highly achieving people and not all highly achieving people are competitive (Smither and Houston 1992).
}

individuals' skills and competencies. In contrast, such personal development motives are likely to be irrelevant if competition relies on luck and, thus, does not offer opportunities to develop or demonstrate mastery of skills. Varying the degree to which a competition depends on individuals' skills, therefore, provides a way to indirectly identify the potential influence of personal development motives and achievement motivation on individuals' tendencies to enter competitions.

Being able to conceptually distinguish different motivations for entering competition does not imply that such a distinction is meaningful with respect to predicting individuals' economic behavior, i.e., that there is some external validity and practical relevance of these distinctions. Bönte et al. (2017a), however, demonstrate that competitiveness resulting from personal development motives displays substantially different associations with basic personality dimensions (Big Five) compared to competitiveness that does not result from personal development motives. In fact, for neuroticism, they even report opposite signs of the associations with these two facets of competition. Furthermore, Bönte et al. (2017a) report that individual competitiveness related to personal development motives and individual competitiveness not related to personal development relate differently to participants' interest in a managerial career. Hence, distinguishing between the underlying motivations to enter competitions is valid and potentially relevant for individuals' occupational choices.

\subsection{Entrepreneurs' enjoyment of competition}

We claim that the enjoyment of competition is distinct from the desire to win and from personal development motives. It is, thus, independent of confidence in winning and independent of whether a given task depends on one's skills and competencies or on pure chance. In particular, we now argue that entrepreneurs may display enjoyment of competition, leading to selection into entrepreneurship as a competitive environment (Kirzner 1972). Entrepreneurs tend to face market competition more directly than wage-earning employees, as illustrated by Bartling et al. (2009, p.93): "a self-employed lawyer is in constant competition for clients, whereas a lawyer working as a civil servant in a public authority is not." Both the desire to win and achievement motivations may make entrepreneurial individuals more likely to enter competitive environments. Whether 
entrepreneurs also demonstrate higher levels in the third facet of individual competitiveness is yet to be investigated. We argue that entrepreneurs' higher enjoyment of competition, independent of potential differences in desires to win and desires to master tasks and demonstrate skills, might be another mechanism that explains why entrepreneurs are observed to start businesses despite low odds of success (Koellinger et al. 2007). Given that success as an entrepreneur depends not only on skills and competencies but also on chance (Monsen and Urbig 2009), enjoyment of competition might be a particularly interesting explanation, because it does not require that individuals believe to be in full control of their performances.

Evidence on whether entrepreneurs are more or less likely to enter competition is scarce and evidence, especially on whether or not they enjoy competition itself rather than the desire to win or the related mastery of tasks, is absent. Following psychological research (e.g., Helmreich and Spence 1978; Newby and Klein 2014), Bönte and Piegeler (2013) use cross-sectional and selfreported $^{7}$ data obtained from a large-scale multi-country survey to demonstrate that individuals who prefer selfemployment over wage employment and those who are currently taking the first steps toward starting new ventures also tend to report that they like situations in which they compete with others. Bönte and Piegeler's (2013) study provides no indication regarding the extent to which their measurement of individual competitiveness might be driven by individuals' desires to win and achievement motivations. In fact, examining the relationship between both psychometric self-reported and economic behavioral measurements, Bönte et al. (2017a) report that self-reported measures of individual competitiveness can reflect a wide variety of motives for favoring competition and, in particular, are likely to reflect personal development motives. This is consistent with findings that self-reported attitudes toward competition significantly relate to achievement motivations (Elliot et al. 2018). Furthermore, Bönte and Piegeler (2013) do not control for individuals' desire to win or the heterogeneity in individuals' expectations to win in competitions. Hence, they cannot rule out the possibility that entrepreneurs like competition because they

\footnotetext{
${ }^{7}$ Self-reported measures are sometimes regarded with suspicion in economic research, and behavioral measures of individual competitiveness obtained from incentivized economic experiments are often preferred (e.g., Niederle 2017; Buser et al. 2014).
}

exaggerate their chances of winning these competitions or because of personal development and achievement motives.

Using an economic experiment, Holm and colleagues (2013) provide some evidence that CEOs of Chinese firms, including owner managers and founding managers, are more likely to select competitive over non-competitive payment schemes than a control group of non-CEOs. In their empirical analyses, Holm and colleagues do not control for risk preferences and perceived odds of winning, which, however, is needed to isolate individual competitiveness from risk preferences and overconfidence (Niederle and Vesterlund 2007). Furthermore, since Holm and colleagues employ a quiz task implying that performance is based on individuals' knowledge, the effect might still be driven by CEOs' need for achievement, the need to demonstrate to be better than others. Given that personal development and the desire to win may be related to achievement motivation, which is one of the characteristics most robustly associated with entrepreneurs (Rauch and Frese 2007; Kerr et al. 2018), these confounding effects could explain the findings of both Bönte and Piegeler as well as Holm and colleagues. In sum, because these studies do not control for important confounding effects, such as risk preferences and confidence in winning (Holm et al. 2013) or for alternative motives driving selection into competition, namely, the desire to win and personal development (Holm et al. 2013, Bönte and Piegeler 2013), both Bönte and Piegeler (2013) and Holm and colleagues (2013) provide only limited evidence with respect to entrepreneurs' enjoyment of competition.

When discussing differences in enjoyment of competition between entrepreneurs and non-entrepreneurial individuals, we can distinguish two important reasons for the emergence of such differences. On the one hand, entrepreneurs may be more likely to enjoy competition than non-entrepreneurial individuals because they are regularly exposed to competition and are more accustomed to it than non-entrepreneurs. Accordingly, a higher level of enjoyment of competition observed $e x$ post entrepreneurial experience would be the result of being socialized in entrepreneurship. ${ }^{8}$ On the other hand, individuals who intend to start new ventures may expect that they will be exposed to competition and, therefore, those who enjoy competing may be more

\footnotetext{
${ }_{8}^{8}$ Evidence for related effects is reported for risk-taking behavior (e.g., Brachert et al. 2017).
} 
likely to become entrepreneurs. Consequently, a higher level of enjoyment of competition observed ex-ante entrepreneurial experience would then be a reason for selecting into entrepreneurship in the first place rather than a consequence of being an entrepreneur.

In order to distinguish between enjoyment of competition observed ex-post entrepreneurial experience and ex-ante entrepreneurial experience, we compare revealed entrepreneurs (individuals with entrepreneurial experience) with potential entrepreneurs, i.e., individuals who consider entrepreneurship as a possible future option but who do not have entrepreneurial experience. Furthermore, these two groups of entrepreneurial individuals are compared with non-entrepreneurial individuals. This allows us to exclude explanations for the association between being an entrepreneurial individual and the likelihood of selecting into more competitive environments that are based on reverse causality. If enjoyment of competition is not the result of entrepreneurial experience but a potential driver of selection into entrepreneurship, both revealed entrepreneurs and potential entrepreneurs will be more likely to select into competitive environments than non-entrepreneurial individuals because they enjoy competitive environments more than non-entrepreneurial individuals. The following two hypotheses summarize our discussion.

\section{Hypothesis 1: Revealed entrepreneurs are more like- ly to select into competition than non-entrepreneurial individuals, independent of confidence in winning and independent of whether performing a task that depends on skills or chance only. \\ Hypothesis 2: Potential entrepreneurs are more like- ly to select into competition than non-entrepreneurial individuals, independent of confidence in winning and independent of whether performing a task that depends on skills or chance only.}

\section{Study design}

\subsection{Identification of enjoyment of competition}

We examine differences between individual competitiveness of entrepreneurs (revealed and potential) and non-entrepreneurial individuals based on a behavioral measure of individual competitiveness. This behavioral measure is obtained from an artificially created environment, i.e., a lab-in-the field study, that ensures comparability of responses even between individuals with highly heterogeneous experiences and personal backgrounds. ${ }^{9}$ Participants choose whether they want to be paid for their performance in a task according to either a competitive or a non-competitive payment scheme (Niederle and Vesterlund 2007). To avoid social desirability biases and common method variance, participation was anonymous (Podsakoff et al. 2003). In order to relate our study to existing experimental studies on individual competitiveness, we follow previous research and employ a simple math task (Niederle and Vesterlund 2010). While the tasks require particular skills, i.e., basic mathematical abilities, and involve risks, i.e., rolling dice that is based on chance, these characteristics are equally unrelated to having either being employed or being an entrepreneur. Thereby, differences in participants' experiences (as entrepreneur or employee) are unlikely to change the subjective framing and interpretation of the artifactual decision situation and, hence, related confounding effects are reduced and measurements are comparable. ${ }^{10}$

\footnotetext{
${ }^{9}$ Some researchers refer to this kind of study, employing control to reduce variation by establishing an artifactual environment and, thereby, reduce unobserved heterogeneity, as an experiment (e.g. Weitzel et al. 2010; Urbig et al. 2012). This approach is consistent with defining an experiment as "an investigation where the system under study is under the control of the investigator" (Cox and Reid 2000: 1; Morgan and Winship 2014: 7). Experiments in a stricter sense, however, require investigators' enacted discretion to change settings and, hence, to actively create heterogeneity that is independent of confounds, thereby allowing the analysis to be freed from the influence of unobserved heterogeneity. Since the key focal relationship of this study does not involve an active manipulation, this study is best described as an artifactual field study or a lab-in-the-field study. Our study involves the creation of distinct treatments, but only in order to demonstrate that a likely confounding effect, due to the specificity of the task that people are competing in, is not present.

${ }^{10}$ To be more specific, if we employed task and game structures that mirror closely the context of an entrepreneur or use a corresponding framing, then participants' understanding of the situation may differ depending on how they interpret the situation. Not only might different entrepreneurs, based on differences in their social identities, associate different intensities of competition with the same entrepreneurial context (Fauchart and Gruber 2011), but — compared to non-entrepreneurs and potential entrepreneurs - they also build on a much more nuanced and less ambiguous background knowledge of the entrepreneurial environment. Entrepreneurs, thus, very likely would frame and understand the situation within the behavioral measurement of competitiveness in different ways than those who have never been in an entrepreneurial context. Hence, resulting differences in measured competitiveness might not only result from differences in competitive preferences, but also from confounding differences in identities related to and knowledge about entrepreneurship.
} 
Our theoretical considerations suggest, however, that a participant's decision to enter a competition may not just depend on enjoyment of competition but also on the two other facets of competition, namely development motives and the desire to win. In order to exclude the possibility that potential differences in individual competitiveness between entrepreneurs and non-entrepreneurial individuals can be explained by these two facets, we slightly adjust an often used behavioral measure of individual competitiveness and conduct regression analyses in order to control for relevant confounds.

First, we introduce an alternative task where participants' performances are not influenced by their efforts, skills, and abilities. To remove the potential influence of individual considerations related to efforts, skills, and abilities as well as related desires and needs, we employ rolling dice as a task (cf., Ifcher and Zarghamee 2016). ${ }^{11}$ By definition, individuals' performances in dice competition are determined by chance only. ${ }^{12}$ Consequently, it can be expected that the decision to enter a dice competition is not influenced by personal development and achievement motivations.

Second, we indirectly control for the desire to win as a motive for selection into competition. Since winning requires competing, the desire to win can create an incentive to enter a competition, which, however, is conditioned on an individual's expectation to win. Individuals with a strong desire to win may be more likely to enter a competition if they expect to win the competition, but expecting to lose would deter their entry into a competition. Therefore, revealed and potential entrepreneurs may be more likely to enter a competition than nonentrepreneurial individuals because they have a stronger

\footnotetext{
${ }^{11}$ Ifcher and Zarghamee (2016) demonstrate that a dice competition is sufficient to generate gender-variant preferences for competition, even when controlling for risk preferences.

${ }^{12}$ One might be tempted to conclude that competing based on rolling dice might remove any element of competition and, hence, attitudes toward competition might no longer be relevant, just risk preferences (cf., Große and Riener 2010). However, the situation is still interactive in the sense that outcomes for one individual depend on outcomes of other individuals, such that one loses when the other wins. Based on a perspective that individuals only maximize their own expected payoffs, this situation clearly is equivalent to a complex lottery. Enjoyment of competition, however, as defined above (cf., Deutsch 1949; Lazear 1999; Smither and Houston 1992), deviates from such a perspective, such that individuals derive a utility from the particular structure of the institutional regime that they are embedded in as well as from the fact that outcomes of individuals they are interacting with are negatively related to the own outcomes. See Ifcher and Zarghamee (2016) for an alternative discussion of why competition based on rolling dice is not the same as a lottery.
}

desire to win and expect to win the competition. This would imply that the effect of entrepreneurship on selection into the math or the dice competition is moderated by the expected probability of winning and vice versa. Thus, in order to control for unobserved differences in the desire to win, we take this into account by not only including the individual confidence in winning in our regressions but also its interaction with being an entrepreneur. If entrepreneurs are more likely to enter a competition than non-entrepreneurial individuals because of a stronger desire to win, the estimated effect of this interaction will be positive and statistically significant.

\subsection{Sample and procedures}

We conducted a "lab-in-the-field" study in a shopping mall in a large German city over the course of three days in June and October 2014. To provide low barriers to participation, we conducted the experiment using a paper-and-pencil approach. The experimental design focused on measuring individuals' tendencies to select into competition under various conditions. Mall visitors were approached and asked whether they would like to participate in an experiment on "decision-making behavior of adults" lasting 10-15 min, where they could earn between at least $€ 5.00$ and at maximum $€ 15.50$. In total, 224 adults participated: 113 men and 111 women. We started with a brief survey to collect data on each participant's socio-economic background, e.g., age, education, and occupation as well as self-reported propensity to take risks, which serve as control variables.

After completing the brief survey, which familiarized participants with the interview situation, they played two rounds of an incentivized competition game, where they chose between a competitive winner-takes-all tournament payment scheme and a non-competitive piecerate payment scheme. ${ }^{13}$ In each round, individuals had

\footnotetext{
${ }^{13}$ One might suspect that asking for the job and entrepreneurial intentions before the experiment might through priming affect behavior in the experiment. Asking for gender, which even lay people associated with differences in competitive behavior, before playing competitions, however, is not found to affect competitive behavior in economic experiments (Boschini et al. 2018). Arguably, both the fact that the artificial experiment involving a competition based on math tasks or rolling-dice (not involving any investments, creative performance, or any business decisions) is sufficiently different from entrepreneurial environments as well as the incentives for the experiment should reduce potential priming effect. Furthermore, asking for entrepreneurial intentions after the incentivized experiment would, due to having no incentives on the measurement of entrepreneurial intentions, be even more susceptible to related priming effects.
} 
to perform a different task, such that their decisions to select or avoid competition are based on a skilldependent task (involving math) or a skill-independent task (rolling dice). Participants were informed that at the end of the experiment, only one of the two rounds would be randomly drawn and paid for in cash. The order of tasks was randomized. Following Mayr et al. (2012), participants in the math task verified up to 20 simple equations within 30 seconds. Each equation consisted of four single digits added or subtracted and a positive result of one or two digits (e.g., " $7+2+3-6=5$. Is the result true or false?"). The sets of 20 equations were randomly composed and randomly assigned. Equations were equally difficult mathematically. One out of every two equations was wrong, but these odds were not revealed to participants. A correctly verified equation added one point to the participant's score, while an incorrect verification subtracted one point. No performance feedback was provided before the end of the experiment. In the dice task, participants rolled five times a pair of fair six-sided dice (with three white and three black sides), earning one point for each die that displays a black side (cf., Ifcher and Zarghamee 2016).

At the beginning of each round, participants were shown a task description, which included examples. Participants then had to choose between a noncompetitive payment scheme, i.e., a piece rate of $€ 0.25$ per point, and a competitive payment scheme, i.e., $€ 0.50$ per point if their own overall score was higher than the score of a randomly selected anonymous participant, and $€ 0$ otherwise. The results achieved by previous participants were noted on cards. Each competitor's score was randomly drawn from a pool of 10 previous participants' scorecards and not shown to participants before the end of the experiment. ${ }^{14}$ Subsequently, participants performed the respective task.

\subsection{Variables}

\subsubsection{Selecting into a competitive environment}

An individual's tendency to select into competitive environments is measured based on the above-introduced

\footnotetext{
${ }^{14}$ One might argue that enjoyment of competition might be different if competing individuals would see one another. However, since competition in business is often indirect, through customers and market interaction, we consider this appropriate when measuring enjoyment of competition as relevant for entrepreneurial and business-related settings.
}

incentivized economic experiment (c.f., Buser et al. 2014). We used a dummy variable indicating whether participants chose the competitive payment (1) or the non-competitive piece-rate payment scheme (0).

While participants had to choose between a competitive winner-takes-all and a piece-rate payment scheme, forced choices of indifferent participants are less informative and may attenuate the effects. To separate clearcut preferences from possibly random choices in cases of indifference, we asked participants to indicate on a scale running from 0 (indifference) to 10 (alternative would not even be considered) the extent to which they actually preferred the chosen payment scheme. We classified decisions where individuals indicated that it was equally likely they would have selected the alternative payment scheme as indifference decisions.

As the competitive payment scheme was characterized by a wider spread of possible payoffs and the probability of receiving the payoff additionally depended on others' performances, the selection of the more competitive payment scheme might reflect not only individual differences in enjoyment of competition but also individual differences regarding both risk preferences and confidence in performing better than others, which reflect characteristics that are also associated with entrepreneurs (cf., Cameron \& Lovallo, 1999; Wu and Knott 2006). To control for these potentially confounding effects, we follow standard practice (e.g., Niederle and Vesterlund 2007) and statistically control for both effects as described below.

\subsubsection{Revealed and potential entrepreneurs versus non-entrepreneurs}

To identify revealed entrepreneurs, we asked participants to indicate whether they were currently selfemployed or had ever been self-employed before.

Within the group that denied both, we separated potential entrepreneurs from unambiguously non-entrepreneurial individuals. We included a three-item measure of entrepreneurial intentions that refers to the potential of future entrepreneurship. We took two items from Thompson (2009): "I intend to set up a company in the future" and "I spend time learning about starting a firm." As a third item, we included "I frequently think about starting my own business." Participants responded on a 7-point scale ranging from "does not apply at all" (1) to "fully applies" (7); responses were averaged (Cronbach's $\alpha=0.84$ ). We classified those who had not been entrepreneurs and displayed the lowest possible score on each of the three 
items as non-entrepreneurial individuals. These individuals unambiguously reject entrepreneurship as an option for the future; they are not at all intending, are not at all preparing themselves, and are clearly not thinking about starting an own business. Despite this very strong criterion, about $30 \%$ of all participants fall into this category. Individuals, who indicated for at least one of these items that they do not clearly reject it, might, in fact, see a chance to engage in entrepreneurship in one way or another. ${ }^{15}$ These individuals are classified as potential entrepreneurs. The 224 participants were partitioned correspondingly into three groups: non-entrepreneurial individuals (67), potential entrepreneurs (100), ${ }^{16}$ and revealed entrepreneurs (57).

As a robustness check, we furthermore explore heterogeneity within the groups of potential entrepreneurs and revealed entrepreneurs and test whether the effects differ for relevant subgroups. To explore if the effect differs within the group of potential entrepreneurs depending on their specific level of the entrepreneurial intent, we split the group of potential entrepreneurs into two subgroups of low entrepreneurial intentions $(N=51$ with average intention $=1.91$ ) versus high entrepreneurial intentions $(N=49$ with average intention $=4.41)$. The split is based on the median by assigning those with an entrepreneurial intention less or equal to the median to the subgroup with low intentions and the others to the group with high intentions. Furthermore, we split the group of revealed entrepreneurs into two subgroups of those who are still with their own business (25) and those who are no longer running their own business (32). Observing 25 current entrepreneurs among our 224 participants leads to a rate of self-employment in our sample of $11.2 \%$, which closely matches the rate of $11.0 \%$ reported by the OECD for Germany for the year of our data collection. ${ }^{17}$

\subsubsection{Control variables}

To measure individuals' confidence in terms of beliefs about the winning probabilities, we asked them to

\footnotetext{
$\overline{15}$ Among the 100 potential entrepreneurs, 89 indicated that they do not fully disagree when being asked about intending to set up a company in the future. Among the other 11 potential entrepreneurs, 9 did not fully reject that they think about starting a firm, and the remaining 2 currently spend time on learning how to start a firm.

${ }^{16}$ For those considering entrepreneurship as a potential future career option, i.e., potential entrepreneurs, this is not necessarily the most preferred or the most likely option and, thus, many of these individuals will not start businesses. However, that is why this group is only referred to as potential entrepreneurs.

${ }^{17} \mathrm{https} / / /$ data.oecd.org/emp/self-employment-rate.htm
}

estimate the number of individuals out of ten potential competitors who, compared with themselves, had an equal or lower score. If participants guessed the number correctly, they received an additional $€ 0.50$ at the end of the experiment.

Risk preferences were elicited through a selfreported measure, which is often used and is demonstrated to be valid (e.g., Caliendo et al. 2009; Dohmen et al. 2011). On a 7-point scale ranging from "does not apply at all" to "fully applies," participants evaluated the following statement: "In general, I am willing to take risks." As context-specific risk preferences might be more relevant than a general risk preference (Bönte et al. 2017a; Caliendo et al. 2009), in a robustness check we controlled for risk-taking that is more specifically related to one's career development and financial issues, respectively, with the following two statements: "For financial investments, I am willing to take risks," and "Within my professional career, I am willing to take risks."

Additionally, we controlled for variables that relate to the specific setup of our behavioral measurement of individual competitiveness. For example, we controlled for whether the dice task or the math task was presented first (order of treatments), the day of data collection, and whether the experimenter was male or female. As demographic control variables, we include dummies for participants' age (classes: below 26, 26-35, 36-45, 4655 , above 55), gender (male vs. female), and the highest level of school education attained, a dummy for having a vocational degree, and a dummy for having a university degree. With respect to secondary schooling, we differentiate between the following types: "less than Hauptschule" (no secondary schooling diploma), "Hauptschule" (grades 5-9, the least demanding level of secondary school), Realschule (grades 5-10), "Fachabitur" (grades 5-11 or 5-12, depending on the federal state), "Abitur" (the highest-level secondary school diploma, grades $5-12$ or $5-13$, depending on the federal state), and a dummy indicating when educational information is missing.

\section{Results}

\subsection{Sample statistics}

Table 1 reports summary statistics for revealed and potential entrepreneurs as well as for non-entrepreneurial 
individuals. ${ }^{18}$ Potential entrepreneurs are substantially younger than revealed entrepreneurs (while $41 \%$ of the potential entrepreneurs are below 26 years old, the share is only $4 \%$ among the revealed entrepreneurs), which is consistent with idea that potential entrepreneurs may, over time, discover suitable opportunities, start businesses, and, hence, with advancing age move into the group of revealed entrepreneurs. Moreover, the share of males is higher among revealed (54\%) and potential (57\%) entrepreneurs than among non-entrepreneurial individuals (37\%), which is consistent with the gender gap in entrepreneurship reported by previous studies (e.g., Bönte and Piegeler 2013). Consistent with findings reported in previous research, we also observe higher preferences for general, financial, and career-related risks among revealed and potential entrepreneurs than among non-entrepreneurs (cf. Caliendo et al. 2009; Bönte et al. 2016). We do not observe, however, statistically significant differences between entrepreneurs and nonentrepreneurial individuals with respect to confidence in winning the math and dice tasks. We also do not observe substantial differences across the three groups of revealed and potential entrepreneurs and non-entrepreneurial individuals with respect to performances in these tasks. ${ }^{19}$

\subsection{Group and treatment comparisons}

Figure 1 illustrates the shares of participants who chose the competitive payment scheme, across the categories of non-entrepreneurial individuals, potential entrepreneurs, and revealed entrepreneurs. Comparing nonentrepreneurial individuals with the combined group of potential and revealed entrepreneurs, we observe a significantly lower proportion choosing the competitive payment scheme for both the math task (two-sample test of proportions, $43 \%$ vs. $57 \% ; z=1.93 ; p=0.05)$ and the

\footnotetext{
${ }^{18}$ While our main focus is on these three groups, Appendix Table 4 further splits the groups of potential and revealed entrepreneurs into those with low versus high entrepreneurial intention and past versus current entrepreneurs respectively. Appendix Table 4 does not reveal surprising or large differences between the subsamples of each group. ${ }^{19}$ A repeated-measure analysis of variance reveals that the difference between performances in math versus dice tasks seems to slightly differ between the three groups of people ( $\mathrm{MS}=10.89, F=2.45, p=0.089$ ). As seen in Table 1 and by post hoc task-specific analyses of variance, indeed the groups' average performances differ slightly in the dice task (MS $=9.08, F=4.14, p=0.017)$ but not in the math task $(\mathrm{MS}=4.36$, $F=0.66, p=0.516$ ). The overall significance level, which accounts for repeated tests, of $p=0.089$, and observing that the effect is related to the dice task and, furthermore, very small, suggests that we face a purely random artifact.
}

dice task (two-sample test of proportions, $43 \%$ vs. $64 \%$; $z=2.92 ; p=0.004)$. While providing initial insights, these tests cannot account for the fact that differences in observed choices may result from differences in risk attitudes or confidence (and the related desire to win) rather than from differences in enjoyment of competition.

\subsection{Regression analyses}

Table 2 reports the results of our regression analyses, which include relevant control variables. Having measured each individual's competitiveness with respect to both the math task and the dice task, we employ random effects logistic regression analyses and include interaction terms to check whether the measures can be pooled. We report coefficients and related standard errors of seven logistic regression models. For the focal effects, i.e., the difference between potential or revealed entrepreneurs and non-entrepreneurial individuals, we additionally report the average marginal effects and robust standard errors. Model 1 indicates that, despite controlling for general risk preferences and confidence, both potential and revealed entrepreneurs select into competition more often than non-entrepreneurial individuals (i.e., 16.1 and 19.5 percentage points, respectively).

Model 2 tests whether the effects differ within the group of potential entrepreneurs depending on their level of entrepreneurial intentions and within the group of revealed entrepreneurs depending on whether they still are entrepreneurs or are no longer running their own business. We introduce a contrast code that is -1 for low intentions and +1 for high intentions and 0 for those who are not potential entrepreneurs. Similarly, we introduce a contract code that is -1 for past entrepreneurs and +1 for current entrepreneurs and 0 for those who are not revealed entrepreneurs. Together with the dummy variables for potential entrepreneurs and for revealed entrepreneurs, these four variables differentiate between the five groups: non-entrepreneurs, potential entrepreneurs with low entrepreneurial intentions, potential entrepreneurs with high entrepreneurial intentions, current entrepreneurs, and past entrepreneurs. With this coding, the coefficients of the two dummies for potential and revealed entrepreneurs reflect the averages of the effects of each of the corresponding two subgroups. The estimated coefficients of the contrast codes reflect how the corresponding two subgroups differ from the corresponding average effects. We do not observe any statistically significant differences within the two groups and the 
Table 1 Summary statistics

\begin{tabular}{|c|c|c|c|}
\hline & Non-entrepreneurs & Potential entrepreneurs & Revealed entrepreneurs \\
\hline Observations & 67 & 100 & 57 \\
\hline \multicolumn{4}{|l|}{ Demographics } \\
\hline Gender: male & $37 \%$ & $57 \%$ & $54 \%$ \\
\hline Age, less than 26 & $19 \%$ & $41 \%$ & $4 \%$ \\
\hline Age, $26-35$ & $13 \%$ & $28 \%$ & $30 \%$ \\
\hline Age, $36-45$ & $24 \%$ & $9 \%$ & $26 \%$ \\
\hline Age, $46-55$ & $24 \%$ & $14 \%$ & $21 \%$ \\
\hline Age, above 55 & $19 \%$ & $8 \%$ & $19 \%$ \\
\hline Education: school-less than Hauptschule & $4 \%$ & $2 \%$ & $4 \%$ \\
\hline Education: school-Hauptschule & $16 \%$ & $10 \%$ & $7 \%$ \\
\hline Education: school—Realschule & $18 \%$ & $15 \%$ & $21 \%$ \\
\hline Education: school—Fachabitur & $12 \%$ & $16 \%$ & $11 \%$ \\
\hline Education: school—Abitur & $45 \%$ & $54 \%$ & $53 \%$ \\
\hline Education: university degree & $37 \%$ & $26 \%$ & $39 \%$ \\
\hline Education: vocational degree & $48 \%$ & $30 \%$ & $58 \%$ \\
\hline Education: education missing & $4 \%$ & $3 \%$ & $5 \%$ \\
\hline Risk preference: general (1-7) & $4.30(\mathrm{SD}=1.46)$ & $4.89(\mathrm{SD}=1.37)$ & $5.18(\mathrm{SD}=1.39)$ \\
\hline Risk preference: financial (1-7) & $2.12(\mathrm{SD}=1.34)$ & $3.03(\mathrm{SD}=1.55)$ & $3.18(\mathrm{SD}=1.79)$ \\
\hline Risk preference: career (1-7) & $3.84(\mathrm{SD}=1.60)$ & $4.63(\mathrm{SD}=1.54)$ & $5.02(\mathrm{SD}=1.70)$ \\
\hline Entrepreneurial intent (1-7) & $1.00(\mathrm{SD}=0.00)$ & $3.13(\mathrm{SD}=1.50)$ & - \\
\hline \multicolumn{4}{|l|}{ Experimental conditions } \\
\hline Day: 1 & $22 \%$ & $28 \%$ & $26 \%$ \\
\hline Day: 2 & $46 \%$ & $49 \%$ & $44 \%$ \\
\hline Day: 3 & $31 \%$ & $23 \%$ & $30 \%$ \\
\hline Male experimenter & $69 \%$ & $71 \%$ & $72 \%$ \\
\hline Math competition second & $51 \%$ & $50 \%$ & $47 \%$ \\
\hline \multicolumn{4}{|l|}{ Participants' responses } \\
\hline Performance in math task $(0-20)$ & $5.42(\mathrm{SD}=2.73)$ & $5.62(\mathrm{SD}=2.63)$ & $5.84(\mathrm{SD}=1.83)$ \\
\hline Performance in dice task $(0-20)$ & $5.48(\mathrm{SD}=1.43)$ & $4.83(\mathrm{SD}=1.58)$ & $4.91(\mathrm{SD}=1.38)$ \\
\hline Confidence for math task $(0-10)$ & $5.37(\mathrm{SD}=1.83)$ & $5.46(\mathrm{SD}=1.68)$ & $5.40(\mathrm{SD}=1.78)$ \\
\hline Confidence for dice task $(0-10)$ & $5.10(\mathrm{SD}=1.24)$ & $5.18(\mathrm{SD}=1.16)$ & $5.05(\mathrm{SD}=1.16)$ \\
\hline Choose competitive payment for math task & $43 \%$ & $57 \%$ & $58 \%$ \\
\hline Choose competitive payment for dice task & $43 \%$ & $64 \%$ & $65 \%$ \\
\hline
\end{tabular}

Reporting mean values for continues variables and percentages for dummy variables, $S D$ standard deviation

effect sizes are small. Hence, the distinction between those who do not consider entrepreneurship a potential option versus those who consider it or have already acted upon and, thereby, revealed their intentions is what drives the difference in behavior.

Model 3 includes terms for interactions between potential entrepreneurs and revealed entrepreneurs with the experimental treatment (dice vs. math). We observe that the differences between entrepreneurs (potential and revealed) and non-entrepreneurial individuals do not depend on whether competitiveness was measured based on a math task or a dice task. Additionally, including interactions for all variables (see the Appendix Table 5) demonstrates that interaction terms with the treatment contrast are insignificant for potential entrepreneurs $(\beta=0.417$, $\mathrm{SE}=0.337, p=0.215)$ and revealed entrepreneurs $(\beta=$ $0.131, \mathrm{SE}=0.378, p=0.729$ ). Conjointly testing these interactions, which reflects a Chow test, shows that these interactions are also not jointly statistically significant $\left(\chi^{2}(20)=13.32, p=0.863\right)$.

By controlling for individuals' confidence in winning, we avoid attributing entrepreneurs' possible 


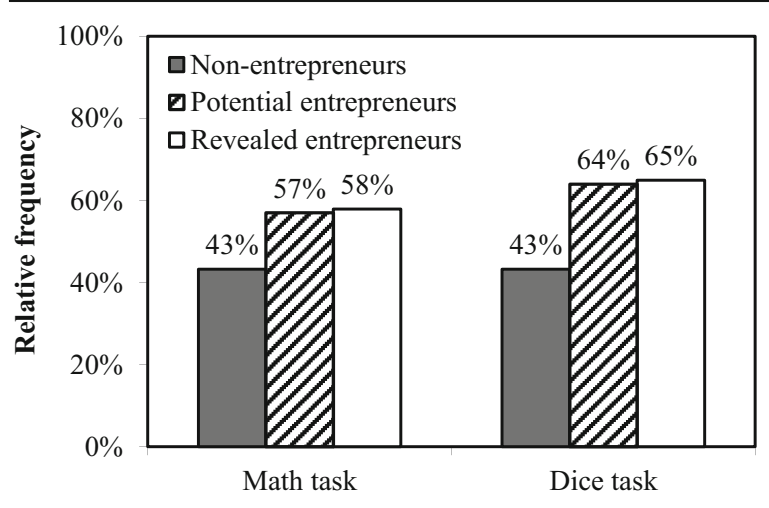

Fig. 1 Relative frequencies of participants choosing the competitive payment scheme

optimism about winning to their enjoyment of competition. This tactic does not, however, enable us to test whether entrepreneurs' individual competitiveness operated independently of their confidence in winning. That is, we cannot exclude the alternative explanation that the willingness to win drives our findings instead of the enjoyment of competition. To demonstrate that entrepreneurs enjoy competition independently of their desire to win, model 4 allows the effects of revealed and potential entrepreneurs to be moderated by confidence in winning. Through the interaction with the confidence in winning, we can identify whether the observed effect is driven by the desire to win (cf., Coffey and Maloney 2010). We observe that the estimated coefficients of interaction terms are not statistically significant. Consequently, the estimated effects of entrepreneurship are not conditioned on confidence and, hence, the observed effects can be considered independent of individuals' confidence and their responses to confidence and, by implication, independent of their potential desire to win.

\subsection{Robustness checks}

In order to explore the robustness of our main results, we ran a set of additional robustness checks (see Table 3). First, regarding payment-scheme decisions, for $11 \%$, that is 51 out of 448 decisions, participants reported that they were in fact indifferent and could as well have taken the alternative payment scheme. Excluding these decisions removes an additional random component from the analyses, which may have led to slightly attenuated effects in our main analysis. Consistent with our intuition, in model 5, we observe slightly stronger effects for both potential and revealed entrepreneurs (i.e., 18.2 and 22.5 percentage points).

Second, while we already controlled for dichotomous differences between potential entrepreneurs with high versus low entrepreneurial intentions, we could also control for the continuous variation in entrepreneurial intent among potential entrepreneurs. In model 6 , we include these entrepreneurial intentions for potential entrepreneurs. We center this variable within the group of potential entrepreneurs, such that the effect of potential entrepreneurs still reflects the effect of the overall group averaged over the subgroups (Cohen et al. 2003). Supporting the analysis based on the dichotomous measure, we also do not observe any effect of the level of entrepreneurial intent for the continuous measure and the focal group differences remain robust (i.e., differences of 16.0 and 19.4 percentage points).

Third, while we controlled for general risk preferences, more specific forms of risk-taking may actually affect entrepreneurial intentions, specifically financial and career-related risk-taking (Bönte et al. 2016; Caliendo et al. 2009). If the related, more specific risk attitudes also affect behavior involved in the behavioral measure of individual competitiveness - e.g., financial risk-taking would be relevant for both entrepreneurship and behavior in financially incentivized experimentsthen general risk-taking might be a weak control variable. Thus, in a robustness check (model 7), we additionally included measures of these more specific risk preferences related to financial and career-related risks. We observe that financial risk-taking indeed is statistically significant and the previously positive but statistically insignificant effect of general risk-taking fully disappears when controlling for financial and careerrelated risk-taking. With respect to our main variables, we observe that the estimated effects of being a potential or of being a revealed entrepreneur decrease slightly when controlling for additional variables. The marginal effect for revealed entrepreneurs declines by 2.5 percentage points (compare models 2 and 4), leaving 16.9 percentage points as a statistically significant effect.

In sum, our results are robust to alternative explanations based on desires to win or achievement motivations as well as robust to several variations in model specification.

\section{Discussion and conclusion}

The results of our lab-in-the field study suggest that entrepreneurs, both revealed and potential, are more 
Table 2 Regression analyses for the choice between competitive and piece-rate payment schemes

\begin{tabular}{|c|c|c|c|c|}
\hline $\begin{array}{l}\text { Dependent variable = "Choose competitive } \\
\text { payment scheme" }\end{array}$ & $\begin{array}{l}\text { Model 1: base } \\
\text { model }\end{array}$ & $\begin{array}{l}\text { Model 2: } \\
\text { heterogeneous } \\
\text { subgroups }\end{array}$ & $\begin{array}{l}\text { Model 3: dice vs. } \\
\text { math task }\end{array}$ & $\begin{array}{l}\text { Model 4: more vs. } \\
\text { less confident }\end{array}$ \\
\hline Potential entrepreneurs & $1.037(0.430)^{*}$ & $1.023(0.429)^{*}$ & $1.032(0.430)^{*}$ & $1.057(0.437)^{*}$ \\
\hline Average marginal effect & $0.161(0.064)^{*}$ & $0.159(0.064)^{*}$ & $0.160(0.064)^{*}$ & $0.161(0.064)^{*}$ \\
\hline Revealed entrepreneurs & $1.266(0.445)^{* *}$ & $1.271(0.443)^{* *}$ & $1.259(0.444)^{* *}$ & $1.258(0.458)^{* *}$ \\
\hline Average marginal effect & $0.195(0.064)^{* *}$ & $0.196(0.064)^{* *}$ & $0.194(0.064)^{* *}$ & $0.197(0.064)^{* *}$ \\
\hline Pot. entrepr:: high vs. low intent & & $-0.101 \quad(0.238)$ & & \\
\hline Diff. in average marginal effects & & $-0.015 \quad(0.036)$ & & \\
\hline Rev. entrepr.: Current vs. past & & $0.148 \quad(0.271)$ & & \\
\hline Diff. in average marginal effects & & $0.022(0.041)$ & & \\
\hline
\end{tabular}

Pot. entrepr. $\times$ dice vs. math task

Rev. entrepr. $\times$ dice vs. math task

$0.179(0.282)$

Pot. entrepr. $\times$ confidence

0.193 (0.338)

Rev. entrepr. $\times$ confidence

Dice vs. math task

Confidence

Risk-taking: general

Gender: male

Age, 26-35

Age, 36-45

Age, 46-55

Age, above 55

Education: school-Hauptschule

Education: school-Realschule

Education: school-Fachabitur

Education: school—Abitur

Education: university degree

Education: vocational degree

Education: education missing

Math competition second

Day: 2

Day: 3

Male experimenter

Constant

lnsig2u

Observations (individuals)

Log-Pseudo Likelihood $\left(\chi^{2}\right)$

\begin{tabular}{|c|c|c|c|c|c|c|c|}
\hline & & & & 0.179 & $(0.282)$ & & \\
\hline & & & & 0.193 & $(0.338)$ & & \\
\hline & & & & & & -0.077 & $(0.244)$ \\
\hline & & & & & & 0.280 & $(0.272)$ \\
\hline 0.233 & $(0.125)^{+}$ & 0.233 & $(0.125)^{+}$ & 0.104 & $(0.214)$ & 0.231 & $(0.125)^{+}$ \\
\hline 0.551 & $(0.118)^{* * *}$ & 0.548 & $(0.118)^{* * *}$ & 0.549 & $(0.117)^{* * *}$ & 0.523 & $(0.183)^{* *}$ \\
\hline 0.103 & $(0.117)$ & 0.109 & (0.119) & 0.104 & $(0.117)$ & 0.099 & $(0.117)$ \\
\hline 0.420 & $(0.325)$ & 0.414 & $(0.322)$ & 0.422 & $(0.325)$ & 0.415 & $(0.327)$ \\
\hline-1.384 & $(0.534)^{* *}$ & -1.368 & $(0.529)^{* *}$ & -1.382 & $(0.534)^{* *}$ & -1.375 & $(0.533)^{* *}$ \\
\hline-1.966 & $(0.590) * * *$ & -1.982 & $(0.589)^{* * *}$ & -1.966 & $(0.590)^{* * *}$ & -2.052 & $(0.602) * * *$ \\
\hline-0.969 & $(0.614)$ & -0.983 & $(0.610)$ & -0.968 & $(0.615)$ & -0.984 & $(0.611)$ \\
\hline 0.541 & $(0.657)$ & 0.499 & $(0.652)$ & 0.542 & $(0.658)$ & 0.562 & $(0.662)$ \\
\hline-0.873 & $(1.471)$ & -0.908 & $(1.470)$ & -0.867 & (1.469) & -0.797 & (1.495) \\
\hline-0.758 & (1.409) & -0.795 & (1.407) & -0.751 & (1.406) & -0.677 & (1.435) \\
\hline-0.819 & $(1.430)$ & -0.868 & (1.426) & -0.813 & (1.428) & -0.798 & (1.458) \\
\hline-1.010 & $(1.376)$ & -1.046 & (1.371) & -0.999 & (1.373) & -0.970 & (1.401) \\
\hline 1.070 & $(0.496)^{*}$ & 1.070 & $(0.492)^{*}$ & 1.068 & $(0.496)^{*}$ & 1.089 & $(0.498)^{*}$ \\
\hline 0.709 & $(0.506)$ & 0.722 & $(0.502)$ & 0.711 & $(0.507)$ & 0.720 & $(0.508)$ \\
\hline-19.838 & $(8.461)^{*}$ & -19.977 & $(8.367)^{*}$ & -19.829 & $(8.469)^{*}$ & -20.094 & $(8.509)^{*}$ \\
\hline 0.234 & $(0.326)$ & 0.225 & $(0.326)$ & 0.233 & $(0.326)$ & 0.257 & $(0.332)$ \\
\hline 0.092 & $(0.425)$ & 0.093 & $(0.424)$ & 0.095 & $(0.425)$ & 0.071 & $(0.426)$ \\
\hline 0.061 & $(0.463)$ & 0.067 & $(0.459)$ & 0.061 & $(0.463)$ & 0.050 & $(0.465)$ \\
\hline-0.140 & $(0.358)$ & -0.153 & $(0.360)$ & -0.134 & $(0.358)$ & -0.131 & $(0.363)$ \\
\hline-0.268 & (1.663) & -0.234 & (1.661) & -0.283 & (1.661) & -0.292 & (1.681) \\
\hline 0.630 & $(0.468)$ & 0.619 & $(0.469)$ & 0.634 & $(0.467)$ & 0.653 & $(0.466)$ \\
\hline 448 & (224) & 448 & (224) & 448 & (224) & 448 & (224) \\
\hline 256.47 & $(44.31)^{* *}$ & -256.27 & $(45.18)^{* *}$ & -256.23 & $(44.67)^{* *}$ & -255.49 & $(43.59) * *$ \\
\hline
\end{tabular}

Robust standard errors are shown in parentheses. Non-entrepreneurs are the base group for the effects of potential and revealed entrepreneurs. Base groups for control variables are the following: age: less than 26; education: school—less than Hauptschule; and day: 1

Significance levels: $* * * p<0.001 ; * * p<0.01 ;{ }^{*} p<0.05 ;{ }^{+} p<0.1$

likely than non-entrepreneurial individuals to choose competitive payment schemes in experimental settings, irrespective of their confidence in winning and irrespective of whether the task in which they compete relates to their skills or to chance alone. This suggests that entrepreneurs' selection into competitive situations is driven by their enjoyment of competition rather than motives related to personal development or willingness 
Table 3 Additional robustness checks

\begin{tabular}{|c|c|c|c|c|c|c|}
\hline \multirow{2}{*}{$\begin{array}{l}\text { Dependent variable }=\text { "Choose competitive payment scheme" } \\
\text { Potential entrepreneurs }\end{array}$} & \multicolumn{2}{|c|}{$\begin{array}{l}\text { Model 5: excluding } \\
\text { decisions under } \\
\text { indifferences }\end{array}$} & \multicolumn{2}{|c|}{$\begin{array}{l}\text { Model 6: continuous } \\
\text { entrepreneurial intent }\end{array}$} & \multicolumn{2}{|c|}{$\begin{array}{l}\text { Model 7: including } \\
\text { context-specific risk- } \\
\text { taking }\end{array}$} \\
\hline & 1.320 & $(0.550)^{*}$ & 1.033 & $(0.430)^{*}$ & 0.794 & $(0.424)^{+}$ \\
\hline Average marginal effect & 0.182 & $(0.072)^{*}$ & 0.160 & $(0.064)^{*}$ & 0.122 & $(0.065)^{+}$ \\
\hline Revealed entrepreneurs & 1.640 & $(0.566)^{* *}$ & 1.258 & $(0.444)^{* *}$ & 1.107 & $(0.436)^{*}$ \\
\hline Average marginal effect & 0.225 & $(0.071)^{* *}$ & 0.194 & $(0.064)^{* *}$ & 0.169 & $(0.064)^{*}$ \\
\hline Pot. entrepr.: entrepreneurial intention & & & -0.048 & $(0.155)$ & & \\
\hline Dice vs. math task & 0.170 & $(0.143)$ & 0.233 & $(0.125)^{+}$ & 0.222 & $(0.125)^{+}$ \\
\hline Confidence & 0.641 & $(0.143)^{* * *}$ & 0.551 & $(0.118)^{* * *}$ & 0.520 & $(0.116)^{* * *}$ \\
\hline Risk-taking: general & 0.131 & $(0.143)$ & 0.112 & $(0.118)$ & -0.009 & $(0.147)$ \\
\hline Risk-taking: financial & & & & & 0.311 & $(0.109)^{* *}$ \\
\hline Risk-taking: career & & & & & -0.003 & $(0.130)$ \\
\hline Gender: male & 0.262 & $(0.396)$ & 0.419 & $(0.324)$ & 0.353 & $(0.322)$ \\
\hline Age, 26-35 & -1.547 & $(0.648)^{*}$ & -1.396 & $(0.534)^{* *}$ & -1.590 & $(0.542)^{* *}$ \\
\hline Age, $36-45$ & -2.093 & $(0.732)^{* *}$ & -1.970 & $(0.590)^{* * *}$ & -1.987 & $(0.594)^{* * *}$ \\
\hline Age, $46-55$ & -1.152 & $(0.789)$ & -0.981 & $(0.614)$ & -1.114 & $(0.619)^{+}$ \\
\hline Age, above 55 & 0.791 & $(0.827)$ & 0.514 & $(0.663)$ & 0.333 & $(0.647)$ \\
\hline Education: school-Hauptschule & -0.698 & $(1.710)$ & -0.871 & $(1.466)$ & -0.826 & $(1.522)$ \\
\hline Education: school—Realschule & -0.823 & $(1.587)$ & -0.767 & $(1.403)$ & -0.781 & $(1.475)$ \\
\hline Education: school—Fachabitur & -0.909 & $(1.614)$ & -0.834 & $(1.426)$ & -0.821 & $(1.483)$ \\
\hline Education: school—Abitur & -1.009 & $(1.550)$ & -1.015 & $(1.370)$ & -1.076 & $(1.437)$ \\
\hline Education: university degree & 1.326 & $(0.604)^{*}$ & 1.075 & $(0.495)^{*}$ & 1.046 & $(0.485)^{*}$ \\
\hline Education: vocational degree & 0.710 & $(0.615)$ & 0.721 & $(0.504)$ & 0.638 & $(0.510)$ \\
\hline Education: education missing & -21.914 & $(10.216)^{*}$ & -19.952 & $(8.430)^{*}$ & -18.918 & $(8.444)^{*}$ \\
\hline Math competition second & 0.191 & $(0.394)$ & 0.234 & $(0.326)$ & 0.217 & $(0.326)$ \\
\hline Day: 2 & 0.307 & $(0.492)$ & 0.095 & $(0.425)$ & -0.026 & $(0.417)$ \\
\hline Day: 3 & 0.182 & $(0.554)$ & 0.075 & $(0.462)$ & -0.096 & $(0.458)$ \\
\hline Male experimenter & -0.112 & $(0.444)$ & -0.144 & $(0.358)$ & -0.173 & $(0.362)$ \\
\hline Constant & -0.703 & (1.904) & -0.301 & $(1.654)$ & -0.067 & $(1.690)$ \\
\hline $\operatorname{lnsig} 2 \mathrm{u}$ & 1.095 & $(0.450)^{*}$ & 0.627 & $(0.468)$ & 0.544 & $(0.484)$ \\
\hline Observations (individuals) & 397 & (211) & 448 & (224) & 448 & (224) \\
\hline Log-Pseudo Likelihood $\left(\chi^{2}\right)$ & -221.31 & $(35.80)^{*}$ & -256.43 & $(44.50)^{* *}$ & -252.71 & $(47.12)^{* *}$ \\
\hline
\end{tabular}

Robust standard errors are shown in parentheses. Non-entrepreneurs are the base group for the effects of potential and revealed entrepreneurs. Base groups for control variables are the following: age: less than 26; education: school-less than Hauptschule; and day: 1. In model 5, we excluded decisions under indifference, which relates to choices for which individuals reported having been indifferent. In model 6, entrepreneurial intention of potential entrepreneurs is centered within the group of potential entrepreneurs, such that the effect of the group of potential entrepreneurs still reflect the average effect of all group members

Significance levels: $* * * p<0.001 ; * * p<0.01 ;{ }^{*} p<0.05 ;{ }^{+} p<0.1$

to win. Employing a behavioral measurement approach based on well-defined environments, i.e., the artificially created experiment, adds significantly to our understanding of nature of the link between individual competitiveness and the emergence of entrepreneurship. Our focus on real behavior in a laboratorylike setting helps us to exclude alternative explanations.
The marginal effects of enjoyment of competition we observe after controlling for gender, risk-taking, and confidence (see Table 2), which are between 12 and 18 percentage points for potential entrepreneurs and between 16 and 23 percentage points for revealed entrepreneurs, indicate a substantial relationship between enjoyment of competition and entrepreneurship. These effect sizes are comparable to levels that are observed for 
other variables considered relevant, such as gender differences in competitiveness (e.g., Apicella et al. 2017).

\subsection{Contributions}

Our study makes two major contributions: First, we examine the link between entrepreneurship and individual competitiveness. We contribute to the body of research investigating entrepreneurs' responses to competition by conceptually distinguishing between different facets of competitiveness and by providing empirical evidence that entrepreneurs are more likely to select into competitive environments than non-entrepreneurs because of their enjoyment of competition, a facet of competitiveness for which there is not yet reliable evidence. This study complements previous research examining behavior of entrepreneurs in competition that suggests entrepreneurs tend to be more aggressive, if not ruthless, in competitions (Utsch et al. 1999; Hmieleski and Lerner 2016; Levine and Rubinstein 2017), having a high need for achievement motivation (McClelland 1965; Rauch and Frese 2007), and might be generally more likely to favor competitive over non-competitive environments (Bönte and Piegeler 2013; Holm et al. 2013). Entrepreneurs enjoy competition irrespective of whether they expect to win, which rules out the desire to win as a motivation for entry into competition, and irrespective of the degree to which a task depends on skills, which rules out mastery-related motives, and, more generally, achievement motivations as a reason for entering competition. Thus, possibly excessive market entry by entrepreneurs might not just be explained by possibly unrealistically optimistic beliefs about winning (cf., Camerer \& Lovallo 1999) or less risk aversion (e.g., Caliendo et al. 2009; Wu and Knott 2006), but also might be explained by intrinsic benefits from competing, that is, enjoyment of competition. Considering an intrinsic value from competing itself in addition to corresponding benefits of winning, e.g., in terms of status and prestige, might also explain why entrepreneurs do not give up so easily, once winning becomes less likely, but instead continue competing. Hence, the enjoyment of competition may help us to better understand why entrepreneurs persist in seemingly unfavorable conditions.

Our second contribution is that our analysis of revealed and potential entrepreneurs tentatively suggests that individuals' behavior in economic experiments is related to selection into entrepreneurship. As discussed above, the alternative explanation that selection into competition is driven by entrepreneurial experience cannot explain why we find similar effects for potential entrepreneurs, who have not yet worked as entrepreneurs. Thereby, our study contributes to research linking competitive behavior in economic experiments to selection into more competitive careers, such as managerial positions (Gneezy et al. 2003; Niederle and Vesterlund 2007), careers in financial industries (Reuben et al. 2015), and selection of prestigious academic tracks (Buser et al. 2014). When studying the link between competitiveness and selection into particular industries; for example, future research might additionally control for whether a career will be pursued as an entrepreneur or in paid employment; the relationships may differ substantially. Observing that entrepreneurship is attractive for competitive individuals does not imply that we are suggesting that these entrepreneurs are always competing. To improve the chances of winning within the market, entrepreneurs often start their business as highly cooperative teams and may even cooperate with competitors within markets. Hence, while entrepreneurship seemingly offers opportunities to satisfy needs derived from participating in competitions, it does not imply that entrepreneurs are unwilling to cooperate.

\subsection{Limitations and opportunities for future research}

Although we make relevant contributions to entrepreneurship research and research on occupational choices in general, this study also faces potential limitations and provides pathways for further research. Most importantly, regarding the differences between entrepreneurs and non-entrepreneurs, our study is based on a crosssectional research design. Hence, it should be interpreted cautiously with respect to causality. Nevertheless, observing similar effects for potential and revealed entrepreneurs provides some evidence that enjoyment of competition might affect selection into entrepreneurship. Future research could further examine the causal link between selection into entrepreneurship and individual competitiveness, e.g., through the use of panel data, the identification of potential instrumental variables, or use blockage designs that manipulate essential conditions of an effect of a variable - a variable that itself cannot be manipulated - in order to shed more light on the causality of an effect (e.g., Gielnik et al. 2015).

Furthermore, while we explore some heterogeneity within the groups of potential and revealed entrepreneurs, there might be more relevant unobserved heterogeneity. For instance, in our empirical analysis, we identified 
revealed entrepreneurs based on whether they are or have been involved in running their own business. This may include self-employed people as well as entrepreneurs engaged in growth-oriented start-ups. The degree of competitiveness might be more prevalent among those growth-oriented start-ups than among the self-employed individuals. Furthermore, the revealed entrepreneurial behavior might also result from what is referred to as necessity entrepreneurship; that is, individuals who do not find employed positions and, consequently, must engage in independent, typically self-employed work (Block and Koellinger 2009). As the lack of alternatives has driven these individuals into entrepreneurship, their selection is likely to not be driven by their enjoyment of competition and, hence, they should not display higher levels of enjoyment of competition. Both kinds of heterogeneity most likely attenuate the effects that we observe for the group of revealed entrepreneurs, such that our study is even conservative regarding the true influence of the enjoyment of competition. Future research might be able to explore such heterogeneity in more detail.

There is one form of heterogeneity among entrepreneurs that is related to perceptions of competitive environments, which might moderate the relationship between individual competitiveness and entrepreneurship. In their discussion of entrepreneurial identities and their relationships to individuals' cognition and behavior, Fauchart and Gruber (2011) suggest that entrepreneurs may differ in interpretations of their competitive environments. Some entrepreneurs focus their views on competing firms, whereas others focus on a particular community, or on the society as a whole and, consequently, depending on their focus they may perceive different intensities of competition. While Fauchart and Gruber discuss heterogeneity in identities within the group of entrepreneurs, similar identity-related differences may exist between entrepreneurs and others. Based on a different theoretical discussion, Acs et al. (2016) point to a similar difference. Discussing differences between the type of entrepreneurships that were focal to Isreal M. Kirzner (1973) and Joseph A. Schumpeter (1934), Acs et al. (2016, pp. 37-38) emphasize that Kirzner refers to entrepreneurship as "competition in the market" and Schumpeter refers to "competition for the market," which again implies different perceptions of competitive environments. Hence, considering differences in perceptions of competitive environments may further improve our understanding of the relationship between enjoyment of competition and entrepreneurship.
Furthermore, our study explicitly focuses on the link between selection into entrepreneurship and individuals' selection into competition, but does not aim to examine the link between selection and behavior in competitive environments and individuals' behavior as entrepreneurs, such as their choices of innovation-related or cost-related competitive strategies (e.g., Wijbenga and van Witteloostuijn 2007). Some researchers already link selection into competition in economic experiments to entrepreneurs' behavior, their way of managing businesses, and their performance. For instance, Berge et al. (2015) report that competitiveness measured through such artifactual experiments is positively associated with competitive choices by entrepreneurs (i.e., levels of investment and employment) as well as with entrepreneurial success (i.e., profit and sales). Whether the entrepreneurial activities of more competitive entrepreneurs are more productive or more destructive is not yet tested. However, since competitiveness is linked to the so-called dark triad of narcissism, psychopathy, and Machiavellianism (Houston et al. 2015) and the latter is linked to unproductive entrepreneurship (Hmieleski and Lerner 2016), future research might take a closer look at the potential desirable and undesirable consequences of competitiveness. Furthermore, rather than linking a higher tendency to enter competitive environments to more or less desirable behavior of entrepreneurs, future research might explore related links with experimental measures of behavior within competitions, such as being motivated to invest more effort or even cheat in competitions, which are not yet linked to entrepreneurship or individuals' occupational choices, in general. Over time, we might then be able to actually capture the full complexity of Schumpeter's (1934) description of entrepreneurs' behaviors as driven by "the will to conquer; the impulse to fight, to prove oneself superior to others," which we suggest is linked to three distinct characteristics, that is, entrepreneurs' desire to win, their achievement motivations, and, as demonstrated in this study, their enjoyment of competition.

Acknowledgments The authors are very grateful for the generous financial support from the Dr. Werner Jackstädt-Stiftung through the Jackstädt Center of Entrepreneurship and Innovation Research. The authors acknowledge helpful feedback from David Audretsch, Sarah Kaplan, Anita McGahan, Johanna Mollerstrom, Vera Rocha, and from participants at research seminars at DIW Berlin and GEM, Grenoble, and participants of the 5th IndianaWuppertal Entrepreneurship Research Workshop, 22nd G-Forum, 4th CODE, and 20th VHB-TIE. 


\section{Appendix}

Table 4 Summary statistics for subgroups of potential and revealed entrepreneurs

\begin{tabular}{|c|c|c|c|c|}
\hline & \multicolumn{2}{|c|}{ Potential entrepreneurs } & \multicolumn{2}{|c|}{ Revealed entrepreneurs } \\
\hline & Low intent & High intent & Past & Current \\
\hline Observations & 51 & 49 & 32 & 25 \\
\hline \multicolumn{5}{|l|}{ Demographics } \\
\hline Gender: male & $57 \%$ & $57 \%$ & $53 \%$ & $56 \%$ \\
\hline Age, less than 26 & $39 \%$ & $43 \%$ & $3 \%$ & $4 \%$ \\
\hline Age, $26-35$ & $25 \%$ & $31 \%$ & $41 \%$ & $16 \%$ \\
\hline Age, $36-45$ & $8 \%$ & $10 \%$ & $22 \%$ & $32 \%$ \\
\hline Age, $46-55$ & $14 \%$ & $14 \%$ & $19 \%$ & $24 \%$ \\
\hline Age, above 55 & $14 \%$ & $2 \%$ & $16 \%$ & $24 \%$ \\
\hline Education: school-less than Hauptschule & $0 \%$ & $4 \%$ & $3 \%$ & $4 \%$ \\
\hline Education: school—Hauptschule & $14 \%$ & $6 \%$ & $10 \%$ & $4 \%$ \\
\hline Education: school—Realschule & $18 \%$ & $12 \%$ & $22 \%$ & $20 \%$ \\
\hline Education: school—Fachabitur & $16 \%$ & $16 \%$ & $9 \%$ & $12 \%$ \\
\hline Education: school—Abitur & $53 \%$ & $55 \%$ & $53 \%$ & $52 \%$ \\
\hline Education: university degree & $25 \%$ & $27 \%$ & $41 \%$ & $36 \%$ \\
\hline Education: vocational degree & $29 \%$ & $31 \%$ & $59 \%$ & $56 \%$ \\
\hline Education: education missing & $0 \%$ & $6 \%$ & $3 \%$ & $8 \%$ \\
\hline Risk preference: general (1-7) & $4.47(\mathrm{SD}=1.42)$ & $5.33(\mathrm{SD}=1.18)$ & $4.94(\mathrm{SD}=1.39)$ & $5.48(\mathrm{SD}=1.42)$ \\
\hline Risk preference: financial (1-7) & $2.53(\mathrm{SD}=1.32)$ & $3.55(\mathrm{SD}=1.61)$ & $2.81(\mathrm{SD}=1.75)$ & $3.64(\mathrm{SD}=1.78)$ \\
\hline Risk preference: career (1-7) & $4.35(\mathrm{SD}=1.56)$ & $4.92(\mathrm{SD}=1.48)$ & $4.59(\mathrm{SD}=1.81)$ & $5.56(\mathrm{SD}=1.39)$ \\
\hline Entrepreneurial intent (1-7) & $1.91(\mathrm{SD}=0.44)$ & $4.41(\mathrm{SD}=1.08)$ & - & - \\
\hline \multicolumn{5}{|l|}{ Experimental conditions } \\
\hline Day: 1 & $29 \%$ & $27 \%$ & $25 \%$ & $28 \%$ \\
\hline Day: 2 & $53 \%$ & $45 \%$ & $50 \%$ & $36 \%$ \\
\hline Day: 3 & $18 \%$ & $29 \%$ & $25 \%$ & $36 \%$ \\
\hline Male experimenter & $71 \%$ & $71 \%$ & $66 \%$ & $80 \%$ \\
\hline Math competition second & $55 \%$ & $45 \%$ & $50 \%$ & $44 \%$ \\
\hline \multicolumn{5}{|l|}{ Participants' responses } \\
\hline Performance in math task $(0-20)$ & $5.73(\mathrm{SD}=2.32)$ & $5.51(\mathrm{SD}=2.94)$ & $5.84(\mathrm{SD}=1.83)$ & $6.08(\mathrm{SD}=2.68)$ \\
\hline Performance in dice task $(0-20)$ & $4.94(\mathrm{SD}=1.58)$ & $4.71(\mathrm{SD}=1.58)$ & $4.91(\mathrm{SD}=1.38)$ & $4.92(\mathrm{SD}=1.38)$ \\
\hline Confidence for math task $(0-10)$ & $4.67(\mathrm{SD}=1.81)$ & $4.41(\mathrm{SD}=1.54)$ & $4.72(\mathrm{SD}=1.67)$ & $4.44(\mathrm{SD}=1.94)$ \\
\hline Confidence for dice task $(0-10)$ & $4.78(\mathrm{SD}=1.15)$ & $4.89(\mathrm{SD}=1.17)$ & $5.09(\mathrm{SD}=1.25)$ & $4.76(\mathrm{SD}=1.01)$ \\
\hline Choose competitive payment for math task & $63 \%$ & $51 \%$ & $56 \%$ & $60 \%$ \\
\hline Choose competitive payment for dice task & $63 \%$ & $65 \%$ & $59 \%$ & $72 \%$ \\
\hline
\end{tabular}

Reporting mean values for continues variables and percentages for dummy variables, $S D$ standard deviation 
Table 5 Generalized Chow test based on every variable interacted with a contrast code for dice versus math task

Dependent variable $=$ "Choose competitive payment scheme"
Column 1: Average effects (main effect)
Column 2: Difference in effects (interaction effects)

\begin{tabular}{|c|c|c|c|c|}
\hline Potential entrepreneurs & 1.104 & $(0.478)^{*}$ & 0.417 & $(0.337)$ \\
\hline Revealed entrepreneurs & 1.377 & $(0.492)^{* *}$ & 0.131 & $(0.378)$ \\
\hline Confidence & 0.591 & $(0.141)^{* * *}$ & 0.038 & $(0.114)$ \\
\hline Risk-taking: general & 0.117 & $(0.129)$ & -0.036 & $(0.092)$ \\
\hline Gender: male & 0.495 & $(0.365)$ & -0.216 & $(0.274)$ \\
\hline Age, 26-35 & -1.522 & $(0.589)^{* *}$ & 0.158 & $(0.410)$ \\
\hline Age, $36-45$ & -2.197 & $(0.669)^{* *}$ & 0.240 & $(0.476)$ \\
\hline Age, $46-55$ & -1.053 & $(0.668)$ & -0.512 & $(0.474)$ \\
\hline Age, above 55 & 0.586 & $(0.719)$ & -0.298 & $(0.473)$ \\
\hline Education: school-Hauptschule & -0.897 & $(1.606)$ & 1.251 & $(0.604) *$ \\
\hline Education: school—Realschule & -0.749 & $(1.523)$ & 0.523 & $(0.531)$ \\
\hline Education: school—Fachabitur & -0.833 & $(1.553)$ & 0.446 & $(0.494)$ \\
\hline Education: school—Abitur & -1.027 & $(1.487)$ & 0.580 & $(0.413)$ \\
\hline Education: university degree & 1.143 & $(0.544)^{*}$ & 0.333 & $(0.365)$ \\
\hline Education: vocational degree & 0.720 & $(0.555)$ & 0.789 & $(0.341)^{*}$ \\
\hline Education: education missing & -20.846 & $(9.250)^{*}$ & -9.602 & $(5.559)^{+}$ \\
\hline Math competition second & 0.282 & $(0.358)$ & -0.016 & $(0.271)$ \\
\hline Day: 2 & 0.108 & $(0.466)$ & 0.347 & $(0.324)$ \\
\hline Day: 3 & 0.068 & $(0.512)$ & 0.511 & $(0.386)$ \\
\hline Male experimenter & -0.172 & $(0.386)$ & 0.262 & $(0.295)$ \\
\hline Constant & -3.296 & $(1.935)^{+}$ & -1.400 & $(0.939)$ \\
\hline $\ln \operatorname{sig} 2 \mathrm{u}$ & & 0.956 & $(0.454)^{*}$ & \\
\hline Observations (individuals) & & 448 & $(224)$ & \\
\hline Log-Pseudo Likelihood $\left(\chi^{2}\right)$ & & -249.27 & $(42.97)$ & \\
\hline \multirow[t]{2}{*}{ Joint test of variables (without constant) } & $\chi^{2}(20)=$ & $37.26^{*}$ & $\chi^{2}(20)=$ & 13.32 \\
\hline & $\mathrm{p}=$ & 0.011 & $\mathrm{p}=$ & 0.863 \\
\hline
\end{tabular}

Robust standard errors are shown in parentheses. Non-entrepreneurs are the base group for the effects of potential and revealed entrepreneurs. Base groups for control variables are the following: age: less than 26; education, school-less than Hauptschule; and day: 1. First column reports estimates of average effects (averaged over math and dice treatment). Second column reports estimates of differences between math and dice task using a contrast code with +1 for the math task and -1 for the dice task. The constant for the differences (in column 2) reflects the main effect of the contrast code. The generalized Chow test is the joint test of all the differences between math and dice treatments, that is, all the interaction terms (as reported at the bottom of column 2). While some differences in education are individually statistically significant, overall, the differences are not statistically significant, such that the individual occurrences might be statistical artifacts. The average effects, however, are also jointly statistically significant (see bottom of column 1)

Significance levels: $* * * p<0.001 ; * * p<0.01 ; * p<0.05 ;{ }^{+} p<0.1$

OpenAccessThis article is distributed under the terms of the Creative Commons Attribution 4.0 International License (http:// creativecommons.org/licenses/by/4.0/), which permits unrestricted use, distribution, and reproduction in any medium, provided you give appropriate credit to the original author(s) and the source, provide a link to the Creative Commons license, and indicate if changes were made.

Publisher's note Springer Nature remains neutral with regard to jurisdictional claims in published maps and institutional affiliations.

\section{References}

Acs, Z., Åstebro, T., Audretsch, D., \& Robinson, D. T. (2016). Public policy to promote entrepreneurship: a call to arms. Small Business Economics, 47(1), 35-51.

Almås, I., Cappelen, A. W., Salvanes, K. G., Sorensen, E. O., \& Tungodden, B. (2016). What explains the gender gap in college track dropout? Experimental and administrative evidence. American Economic Review, 106(5), 296-302. 
Apicella, C. L., Demiral, E. E., \& Mollerstrom, J. (2017). No gender difference in willingness to compete when competing against self. American Economic Review, 107(5), 136-140.

Bartling, B., Fehr, E., Maréchal, M. A., \& Schunk, D. (2009). Egalitarianism and competitiveness. American Economic Review: Papers and Proceedings, 99(2), 93-98.

Berge, L. I. O., Bjorvatn, K., Pires, A. J. G., \& Tungodden, B. (2015). Competitive in the lab, successful in the field? Journal of Economic Behavior \& Organization, 118, 303317.

Blanchflower, D. G., \& Oswald, A. J. (1998). What makes an entrepreneur? Journal of Labor Economics, 16(1), 26-60.

Block, J., \& Koellinger, P. (2009). I can't get no satisfactionnecessity entrepreneurship and procedural utility. Kyklos, 62(2), 191-209.

Bönte, W., \& Piegeler, M. (2013). Gender gap in latent and nascent entrepreneurship: driven by competitiveness. Small Business Economics, 41(4), 961-987.

Bönte, W., Procher, V., \& Urbig, D. (2016). Biology and selection into entrepreneurship: the relevance of prenatal testosterone exposure. Entrepreneurship, Theory \& Practice, 40(5), $1121-1148$.

Bönte, W., Lombardo, S., \& Urbig, D. (2017a). Economics meets psychology: experimental and self-reported measures of individual competitiveness. Personality and Individual Differences, 116, 179-185.

Bönte, W., Procher, V. D., Urbig, D., \& Voracek, M. (2017b). Digit ratio (2D: 4D) predicts self-reported measures of general competitiveness, but not behavior in economic experiments. Frontiers in Behavioral Neuroscience, 11, 238.

Boschini, A., Dreber, A., von Essen, E., Muren, A., \& Ranehill, E. (2018). Gender, risk preference and willingness to compete in a random sample of the Swedish population (No. 740). University of Gothenburg, Department of Economics.

Brachert, M., Hyll, W., \& Titze, M. (2017). On the simultaneity bias in the relationship between risk attitudes, entry into entrepreneurship and entrepreneurial survival. Applied Economics Letters, 24(7), 477-480.

Busenitz, L. W., \& Barney, J. B. (1997). Differences between entrepreneurs and managers in large organizations: biases and heuristics in strategic decision-making. Journal of Business Venturing, 12, 9-30.

Buser, T., Niederle, M., \& Oosterbeek, H. (2014). Gender, competitiveness and career choices. Quarterly Journal of Economics, 129(3), 1409-1447.

Buser, T., Peter, N., \& Wolter, S. C. (2017). Gender, competitiveness, and study choices in high school: evidence from Switzerland. American Economic Review., 107(5), 125-130.

Caliendo, M., Fossen, F. M., \& Kritikos, A. S. (2009). Risk attitudes of nascent entrepreneurs-new evidence from an experimentally validated survey. Small Business Economics, 32(2), 153-167.

Camerer, C., \& Lovallo, D. (1999). Overconfidence and excess entry: an experimental approach. The American Economic Review, 89(1), 306-318.

Cassidy, T., \& Lynn, R. (1989). A multifactorial approach to achievement motivation: the development of a comprehensive measure. Journal of Occupational Psychology, 62, 301312 .
Coffey, B., \& Maloney, M. T. (2010). The thrill of victory: measuring the incentive to win. Journal of Labor Economics, 28(1), 87-112.

Cohen, J., Cohen, P., West, S. G., \& Aiken, L. S. (2003). Applied multiple correlation/regression analysis for the behavioral sciences. UK: Taylor \& Francis.

Connelly, B. L., Tihanyi, L., Crook, T. R., \& Gangloff, K. A. (2014). Tournament theory: thirty years of contests and competitions. Journal of Management, 40(1), 16-47.

Cox, D. R., \& Reid, N. (2000). The theory of the design of experiments. Chapman and Hall/CRC.

Croson, R., \& Gneezy, U. (2009). Gender differences in preferences. Journal of Economic Literature, 47(2), 448-474.

Deutsch, M. (1949). A theory of co-operation and competition. Human Relations, 2(3), 129-152.

Dohmen, T., Falk, A., Huffman, D., Sunde, U., Schupp, S., \& Wagner, G. G. (2011). Individual risk attitudes: measurement, determinants, and behavioral consequences. Journal of the European Economic Association, 9(3), 522-550.

Elliot, A. J., \& McGregor, H. A. (1999). Test anxiety and the hierarchical model of approach and avoidance achievement motivation. Journal of Personality and Social Psychology, $76(4), 628$.

Elliot, A. J., Jury, M., \& Murayama, K. (2018). Trait and perceived environmental competitiveness in achievement situations. Journal of Personality, 86(3), 353-367.

Fauchart, E., \& Gruber, M. (2011). Darwinians, communitarians, and missionaries: the role of founder identity in entrepreneurship. Academy of Management Journal, 54(5), 935-957.

Fehr, E., \& Schmidt, K. M. (1999). A theory of fairness, competition, and cooperation. Quarterly Journal of Economics, 817-868.

Gielnik, M. M., Spitzmuller, M., Schmitt, A., Klemann, D. K., \& Frese, M. (2015). "I put in effort, therefore I am passionate": investigating the path from effort to passion in entrepreneurship. Academy of Management Journal, 58(4), 1012-1031.

Gneezy, U., Niederle, M., \& Rustichini, A. (2003). Performance in competitive environments: gender differences. The Quarterly Journal of Economics, 118(3), 1049-1074.

Große, N. D., \& Riener, G. (2010). Explaining gender differences in competitiveness: gender-task stereotypes. Jena economic research papers, No. 2010,017, Univ. [u.a.], Jena.

Hart, J. W., Stasson, M. F., Mahoney, J. M., \& Story, P. (2007). The big five and achievement motivation: exploring the relationship between personality and a two-factor model of motivation. Individual Differences Research, 5(4).

Helmreich, R. L., \& Spence, J. T. (1978). Work and family orientation questionnaire: an objective sinstrument to assess components of achievement motivation and attitudes toward family and career. JSAS Catalog of Selected Documents in Psychology, 8(2), Document MS 1677.

Hmieleski, K. M., \& Lerner, D. A. (2016). The dark triad and nascent entrepreneurship: an examination of unproductive versus productive entrepreneurial motives. Journal of Small Business Management, 54(S1), 7-32.

Holm, H. J., Opper, S., \& Nee, V. (2013). Entrepreneurs under uncertainty: an economic experiment in China. Management Science, 59(7), 1671-1687.

Hönekopp, J., Manning, J. T., \& Müller, C. (2006). Digit ratio (2D: 4D) and physical fitness in males and females: evidence for 
effects of prenatal androgens on sexually selected traits. Hormones and Behavior, 49, 545-549.

Houston, J. M., Mcintire, S. A., Kinnie, J., \& Terry, C. (2002a). A factorial analysis of scales measuring competitiveness. Educational and Psychological Measurement, 62(2), 284-298.

Houston, J., Harris, P., McIntire, S., \& Francis, D. (2002b). Revising the competitiveness index using factor analysis. Psychological Reports, 90(1), 31-34.

Houston, J. M., Queen, J. S., Cruz, N., Vlahov, R., \& Gosnell, M. (2015). Personality traits and winning: competitiveness, hypercompetitiveness, and Machiavellianism. North American Journal of Psychology, 17(1), 105-112.

Ifcher, J., \& Zarghamee, H. (2016). Do gender-variant preferences for competition persist in the absence of performance? Economic Inquiry, 54(4), 1918-1930.

Kerr, S. P., Kerr, W. R., \& Xu, T. (2018). Personality traits of entrepreneurs: a review of recent literature. Foundations and Trends in Entrepreneurship, 14(3), 279-356.

Kirzner, I. M. (1973). Competition and entrepreneurship. Chicago, London: The University of Chicago Press.

Koellinger, P., Minniti, M., \& Schade, C. (2007). "I think I can, I think I can": overconfidence and entrepreneurial behavior. Journal of Economic Psychology, 28(4), 502-527.

Lazear, E. P. (1999). Personnel economics: past lessons and future directions. Journal of Labor Economics, 17(2), 199-236.

Levine, R., \& Rubinstein, Y. (2017). Smart and illicit: who becomes an entrepreneur and do they earn more? The Quarterly Journal of Economics, 132(2), 963-1018.

Manning, J. T., \& Taylor, R. P. (2001). Second to fourth digit ratio and male ability in sport: implications for sexual selection in humans. Evolution and Human Behavior, 22, 61-69.

Marshall, A. (1920). Principles of Economics, 8th ed. London: Macmillan \& Co..

Mayr, U., Wozniak, D., Davidson, C., Kuhns, D., \& Harbaugh, W. T. (2012). Competitiveness across the life span: the feisty fifties. Psychology and Aging, 27(2), 278.

McClelland, D. C. (1965). N achievement and entrepreneurship: a longitudinal study. Journal of Personality and Social Psychology, 1(4), 389.

Miner, J. B., \& Raju, N. S. (2004). Risk propensity differences between managers and entrepreneurs and between low- and high-growth entrepreneurs: a reply in a more conservative vein. Journal of Applied Psychology, 89(1), 3-13.

Monsen, E., \& Urbig, D. (2009). Perceptions of efficacy, control, and risk: a theory of mixed control. In Understanding the entrepreneurial mind (pp. 259-281). New York, NY: Springer.

Morgan, S. L., \& Winship, C. (2014). Counterfactuals and causal inference. Cambridge University Press.

Newby, J. L., \& Klein, R. G. (2014). Competitiveness reconceptualized: psychometric development of the competitiveness orientation measure as a unified measure of trait competitiveness. The Psychological Record, 64(4), 879-895.

Nicholls, J. G. (1984). Achievement motivation: conceptions of ability, subjective experience, task choice, and performance. Psychological Review, 91(3), 328.

Niederle, M. (2017). A gender agenda: a progress report on competitiveness. American Economic Review: Papers \& Proceedings 2017, 107(5), 115-119.

Niederle, M., \& Vesterlund, L. (2007). Do women shy away from competition? Do men compete too much? Quarterly Journal of Economics, 122(3), 1067-1101.
Niederle, M., \& Vesterlund, L. (2010). Explaining the gender gap in math test scores: the role of competition. Journal of Economic Perspectives, 24(2), 129-144.

Palich, L. E., \& Bagby, D. R. (1995). Using cognitive theory to explain entrepreneurial risktaking: challenging conventional wisdom. Journal of Business Venturing, 10(6), 425.

Podsakoff, P. M., MacKenzie, S. B., Lee, J. Y., \& Podsakoff, N. P. (2003). Common method biases in behavioral research: a critical review of the literature and recommended remedies. Journal of Applied Psychology, 88(5), 879.

Rauch, A., \& Frese, M. (2007). Let's put the person back into entrepreneurship research: a meta-analysis on the relationship between business owners' personality traits, business creation, and success. European Journal of Work and Organizational Psychology, 16(4), 353-385.

Reuben, E., Sapienza, P., \& Zingales, L. (2015). Taste for competition and the gender gap among young business professionals. NBER Working Paper No. 21695.

Reuben, E., Wiswall, M., \& Zafar, B. (2017). Preferences and biases in educational choices and labour market expectations: shrinking the black box of gender. The Economic Journal. https://doi.org/10.1111/ecoj.12350.

Ryckman, R. M., Hammer, M., Kaczor, L. M., \& Gold, J. A. (1990). Construction of a hypercompetitive attitude scale. Journal of Personality Assessment, 55(3-4), 630-639.

Ryckman, R. M., Hammer, M., Kaczor, L. M., \& Gold, J. A. (1996). Construction of a personal development competitive attitude scale. Journal of Personality Assessment, 66(2), 374-385.

Schumpeter, J. A. (1934). The theory of economic development. Cambridge, MA: Harvard University Press.

Smither, R. D., \& Houston, J. M. (1992). The nature of competitiveness: the development and validation of the competitiveness index. Educational and Psychological Measurement, 52(2), 407-418.

Thompson, E. R. (2009). Individual entrepreneurial intent: construct clarification and development of an internationally reliable metric. Entrepreneurship Theory and Practice, 33(3), 669-694.

Urbig, D., Weitzel, U., Rosenkranz, S., \& van Witteloostuijn, A. (2012). Exploiting opportunities at all cost? Entrepreneurial intent and externalities. Journal of Economic Psychology, 33(2), 379-393.

Utsch, A., Rauch, A., Rothfufs, R., \& Frese, M. (1999). Who becomes a small scale entrepreneur in a post-socialist environment: on the differences between entrepreneurs and managers in East Germany. Journal of Small Business Management, 37(3), 31-42.

van Lange, P. A., De Bruin, E., Otten, W., \& Joireman, J. A. (1997). Development of prosocial, individualistic, and competitive orientations: theory and preliminary evidence. Journal of Personality and Social Psychology, 73(4), 733-746.

Weitzel, U., Urbig, D., Desai, S., Acs, Z., \& Sanders, M. (2010). The good, the bad, and the talented: entrepreneurial talent and selfish behavior. Journal of Economic Behavior and Organization, 76(1), 64-81.

Wijbenga, F. H., \& van Witteloostuijn, A. (2007). Entrepreneurial locus of control and competitive strategies-the moderating effect of environmental dynamism. Journal of Economic Psychology, 28(5), 566-589.

Wu, B., \& Knott, A. M. (2006). Entrepreneurial risk and market entry. Management Science, 52(9), 1315-1330. 